\title{
Finding efficient frontier of process parameters for plastic injection molding
}

\author{
Wu-Lin Chen ${ }^{1 *}$, Chin-Yin Huang ${ }^{2}$ and Ching-Ya Huang ${ }^{2}$
}

\begin{abstract}
Product quality for plastic injection molding process is highly related with the settings for its process parameters. Additionally, the product quality is not simply based on a single quality index, but multiple interrelated quality indices. To find the settings for the process parameters such that the multiple quality indices can be simultaneously optimized is becoming a research issue and is now known as finding the efficient frontier of the process parameters. This study considers three quality indices in the plastic injection molding: war page, shrinkage, and volumetric shrinkage at ejection. A digital camera thin cover is taken as an investigation example to show the method of finding the efficient frontier. Solidworks and Moldflow are utilized to create the part's geometry and to simulate the injection molding process, respectively. Nine process parameters are considered in this research: injection time, injection pressure, packing time, packing pressure, cooling time, cooling temperature, mold open time, melt temperature, and mold temperature. Taguchi's orthogonal array L27 is applied to run the experiments, and analysis of variance is then used to find the significant process factors with the significant level 0.05. In the example case, four process factors are found significant. The four significant factors are further used to generate $3^{4}$ experiments by complete experimental design. Each of the experiments is run in Moldflow. The collected experimental data with three quality indices and four process factors are further used to generate three multiple regression equations for the three quality indices, respectively. Then, the three multiple regression equations are applied to generate 1,225 theoretical datasets. Finally, data envelopment analysis is adopted to find the efficient frontier of the 1,225 theoretical datasets. The found datasets on the efficient frontier are with the optimal quality. The process parameters of the efficient frontier are further validated by Moldflow. This study demonstrates that the developed procedure has proved a useful optimization procedure that can be applied in practice to the injection molding process.
\end{abstract}

Keywords: Injection molding; Taguchi's orthogonal array; Mutiple regression analysis; Data envelopment analysis; Optimization

\section{Introduction}

Along with the rapid progress of production techniques for high-tech products, better and better quality of products is required for the survival in the current market. Besides providing various functions, the trend of the design for plastic products is light, thin, short, and small. Therefore, the setting of process parameters for plastic products has a remarkable influence on their quality (Huang and Tai 2001).

Injection molding is one of the most important techniques for polymer processing (to manufacture plastic products) because of its high speed for molding and its

\footnotetext{
* Correspondence: wlchen@pu.edu.tw

'Department of Computer Science and Information Management, Providence University, Taichung, Republic of China (Taiwan) Full list of author information is available at the end of the article
}

capability of manufacturing complex geometric shapes of products. Besides, injection molding is capable of mass production, so it is widely used for many products, especially for electronic products, such as computers and communication products. Injection molding is usually adopted to produce thin parts or thin covers for these products.

Currently, there are two categories for the setting of process parameters for injection molding: one is based on the technicians' previous experience and the other takes advantage of mold flow analysis softwares, such as Moldflow (used in this study) to find the initial values for process parameters (by running various simulations on these moldflow analyses). However, no method can quickly find the reasonable combination of process parameters. In addition, trial and error is required for both

\section{实}

(c) 2013 Chen et al.; licensee Springer. This is an Open Access article distributed under the terms of the Creative Commons Attribution License (http://creativecommons.org/licenses/by/2.0), which permits unrestricted use, distribution, and reproduction in any medium, provided the original work is properly cited. 


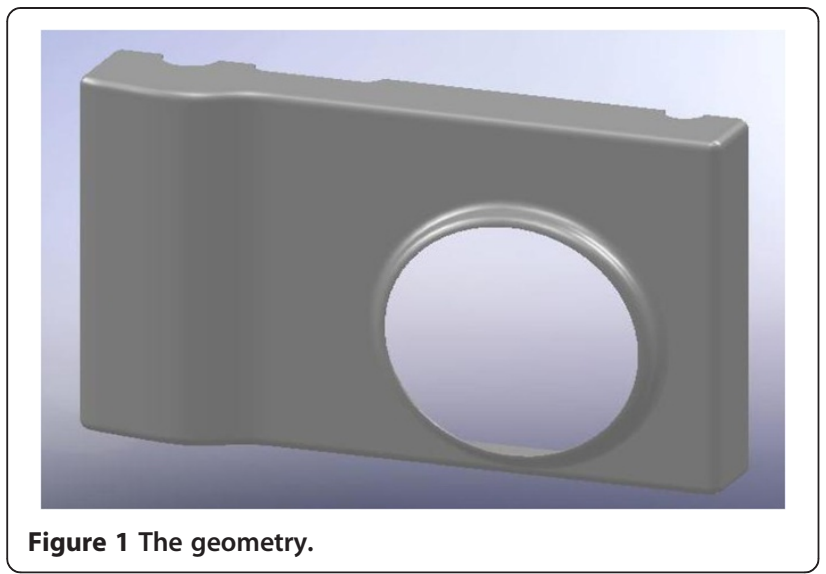

methods, and the process of trial and error consumes a significant amount of time and cost. Therefore, both methods cannot meet the requirement of the current market.

Researchers have applied various kinds of methods, e.g., artificial neural network and/or fuzzy logic (Liao et al. 2004a, b; Kurtaran et al. 2005; Ozcelik and Erzurumlu 2006), genetic algorithm (Kurtaran et al. 2005; Ozcelik and Erzurumlu 2006), design of experiments (Huang and Tai, 2001; Liao et al. 2004a, b), and response surface method (Ozcelik and Erzurumlu 2005; Kurtaran and Erzurumlu 2006; Chen et al. 2010) to optimize the initial process parameter setting of plastic injection molding. However, most studies focus on the single optimal combination of process parameters by different optimization techniques. It is well known that when multiple quality characteristics are considered, the trade-off relationships exist among these quality characteristics, and these relationships make the task of finding the optimal combination rather complicated if not impossible. Instead of finding a single optimal combination of process parameters, this research seeks the efficient frontier of process parameters by data envelopment analysis (DEA).

The remainder of this paper is organized as follows: the 'Literature review on the optimization of process parameters for injection molding' section will review related work in the literature. The properties of the material and product used in this paper will be addressed in the 'Materials and product' section. The 'Experimental design and methodology' section will discuss the experimental design and the procedure of finding the efficient frontier of process parameters. Finally, the summary and concluding remarks are provided in the 'Summary and conclusions' section.

\section{Literature review on the optimization of process parameters for injection molding}

The literature of optimization for injection molding is briefly addressed in this section. Kim and Lee (1997) discussed different geometries for plastic parts to improve the parts' warpage by Taguchi's orthogonal experiment design. To avoid producing flaws of silver streaks for automobile plastic bumpers, Taguchi's optimization method is utilized to decide the optimal values for the process parameters by Chen et al. (1997). The same

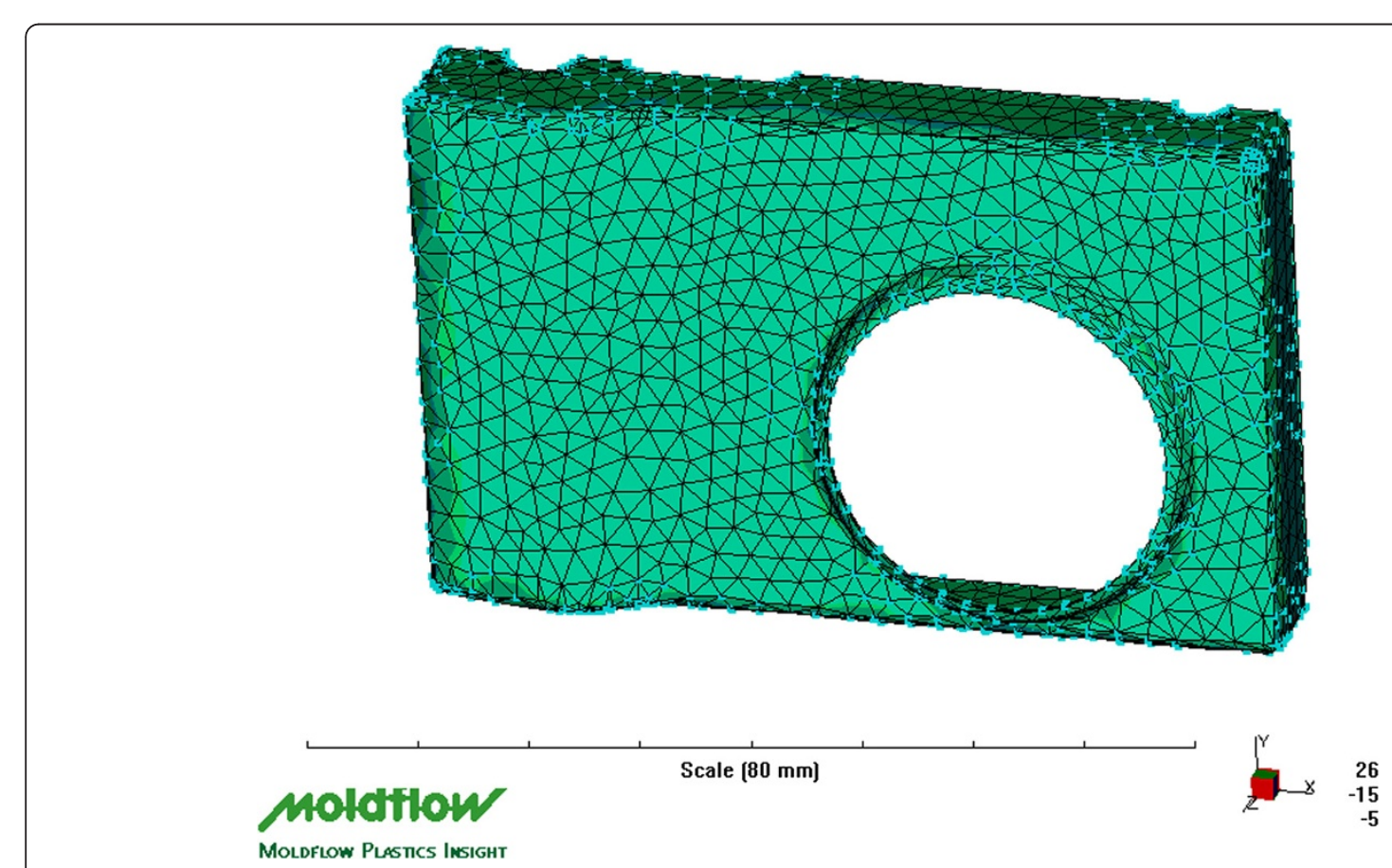

Figure 2 The finite element model. Courtesy of Moldflow Corporation. 


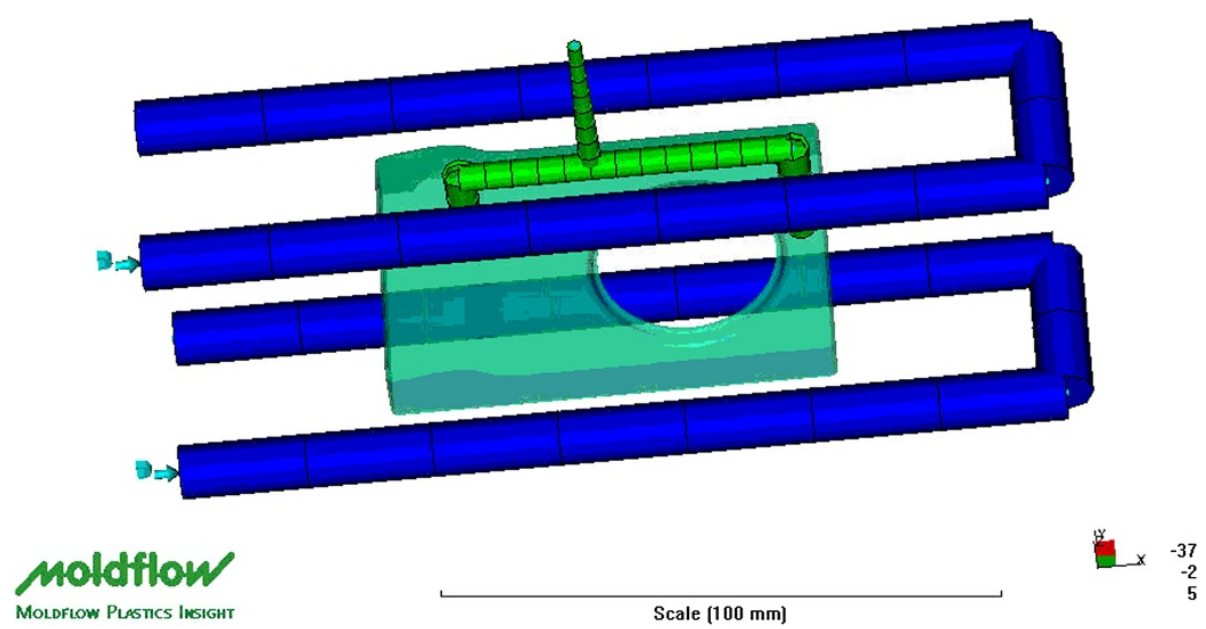

Figure 3 The runner system with the cooling channel. Courtesy of Moldflow Corporation.

optimization method was also used by several works (Huang and Tai 2001; Liu and Chen 2002; Liao et al. 2004a, b; Oktem et al. 2007) to find the optimal combinations of process parameters for different plastic products. In these works, warpages and shrinkages of plastic parts were usually considered as their quality indices. Moldflow, a mold flow analysis software, was used to simulate a real injection machine by Erzurumlu and Ozcelik (2006). Several techniques including the Taguchi's method, the neural networks, and the genetic algorithm were combined to optimize the process parameters.

The response surface methodology (RSM) is another popular method to optimize the process parameters in the literature. The complete model of RSM was first established by Box and Wilson (1951). To improve two quality indices, within-wafer non-uniformity and the removal rate, of the chemical-mechanical planarization process in semiconductor manufacturing, dual RSM was proposed by Fan (2000) to optimize five process parameters. In order to avoid the difficulty of minimizing both quality indices, one was treated as the primary response put in the objective function and the other was the secondary response placed in the constraint. Two works developed RSM combined with different optimization techniques (Ozcelik and Erzurumlu 2006; Chiang and Chang 2007). Chen et al. (2010) applied dual RSM to improve the quality of plastic injection molding. Warpage is the primary response (and is treated as the objective function), while shrinkage is the secondary response (and is then set as the constraint) in their work.

For multiple quality indices, the above two classes of optimization focus on searching the single optimal combination of process parameters. However, it is known that the trade-off relationships exist among multiple quality indices, so the searching task of the single optimum is not easy. Castro et al. (2007) used DEA technique to find the efficient frontier when six quality indices (related with the part's geometry) were considered. This research proposes to combine several techniques including experimental design, analysis of variance (ANOVA), multiple regression analysis, and DEA to find the efficient frontier of the process parameters when three essential quality indices, warpage, shrinkage, and volumetric shrinkage at ejection, are under consideration simultaneously.

\section{Materials and product}

This study demonstrates how to determine the efficient frontier of process parameters for injection molding by taking an example of the thin cover of a digital camera. The CAD software, Solidworks, is the first to prepare the geometry of the product as shown in Figure 1.

Next, the commercial CAE simulation software tool, Moldflow, is utilized to create the finite element model and uses the finite element and finite difference method to solve pressure, flow, and temperature fields of injection molding (Walsh 1993; Mackerle 2005; Shoemaker 2006).

Table 1 Material properties of GE Cycoloy C2950 PC/ABS

\begin{tabular}{lc}
\hline Material property & Value \\
\hline Recommended mold surface temperature $\left({ }^{\circ} \mathrm{C}\right)$ & 70 \\
\hline Recommended melt temperature $\left({ }^{\circ} \mathrm{C}\right)$ & 275 \\
\hline Melt density $\left(\mathrm{g} / \mathrm{cm}^{3}\right)$ & 0.97618 \\
\hline Solid density $\left(\mathrm{g} / \mathrm{cm}^{3}\right)$ & 1.1161 \\
\hline Eject temperature $\left({ }^{\circ} \mathrm{C}\right)$ & 113 \\
\hline Maximum shear stress $(\mathrm{MPa})$ & 0.4 \\
\hline Maximum shear rate $\left(\mathrm{s}^{-1}\right)$ & 40,000 \\
\hline Mold thermal conductivity $\left(\mathrm{W} / \mathrm{m}{ }^{\circ} \mathrm{C}\right)$ & 29 \\
\hline Elastic module $(\mathrm{MPa})$ & 200,000 \\
\hline Poisson's ratio & 0.33 \\
\hline
\end{tabular}


Table 2 Key process parameters and their ranges of operation

\begin{tabular}{llcc}
\hline Parameter & Variable & $\begin{array}{c}\text { Initial } \\
\text { value }\end{array}$ & $\begin{array}{c}\text { Range of } \\
\text { operation }\end{array}$ \\
\hline Injection time & INT $\left(x_{1}\right)$ & $1 \mathrm{~s}$ & 0.5 to $1.5 \mathrm{~s}$ \\
\hline Injection pressure & $\mathrm{INP}\left(x_{2}\right)$ & $120 \mathrm{MPa}$ & 100 to $140 \mathrm{MPa}$ \\
\hline Packing pressure & $\mathrm{PP}\left(x_{3}\right)$ & $100 \mathrm{MPa}$ & 80 to $120 \mathrm{MPa}$ \\
\hline Packing time & $\mathrm{PT}\left(x_{4}\right)$ & $10 \mathrm{~s}$ & 7.5 to $12.5 \mathrm{~s}$ \\
\hline Cooling time & $\mathrm{COTI}\left(x_{5}\right)$ & $19 \mathrm{~s}$ & 14 to $24 \mathrm{~s}$ \\
\hline Coolant temperature & $\mathrm{COTE}\left(x_{6}\right)$ & $25^{\circ} \mathrm{C}$ & $20^{\circ} \mathrm{C}$ to $30^{\circ} \mathrm{C}$ \\
\hline Mold open time & $\mathrm{MOO}\left(x_{7}\right)$ & $5 \mathrm{~s}$ & 4 to $6 \mathrm{~s}$ \\
\hline Melt temperature & MET $\left(x_{8}\right)$ & $275^{\circ} \mathrm{C}$ & $270^{\circ} \mathrm{C}$ to $280^{\circ} \mathrm{C}$ \\
\hline Mold surface & MOTE $\left(x_{9}\right)$ & $70^{\circ} \mathrm{C}$ & $65^{\circ} \mathrm{C}$ to $75^{\circ} \mathrm{C}$ \\
temperature & & & \\
\hline
\end{tabular}

The setting in Moldflow to simulate production of the parts is described below.

Figure 2 shows the finite element model of the plastic part, and Figure 3 is the runner system with the cooling channel. The material used in this paper is GE Cycoloy C2950 PC/ABS (Gardena, CA, USA), and the simulating molding machine used is Roboshot 330i (330 tons, $8.90 \mathrm{oz}$, $44 \mathrm{~mm}$ ) high speed/pressure (Milacron, Cincinnati, $\mathrm{OH}$, USA). Table 1 lists the main properties of the material.

This paper discusses nine key process parameters which are suggested in the literature (Chen and Turng 2005; Chen et al. 2010) because these parameters are most likely to affect products' quality. Table 2 shows nine process parameters and their ranges of operation suggested by Moldflow. Three indices of quality, warpage, shrinkage, and volumetric shrinkage at ejection, are considered in this paper.

The warpages are measured at four reference nodes, and the shrinkages are measured at four edges in this paper; these nodes and edges are depicted in Figure 4 of the $X Y$ horizontal plane. In Figure 4, four reference nodes N1991, N1962, N1955, and N2261 are shown, while four edges are formed by these four nodes and are denoted by E1, E2, E3, and E4, respectively.

\section{Experimental design and methodology}

This section presents how to design the experiment as well as the procedure to determine the efficient frontier of process parameters. In the 'Experimental design' subsection, the experimental design will be addressed. To effectively find the efficient frontier, ANOVA will be firstly executed to determine the significant process parameters out of the original nine process parameters in 'Finding significant process parameters by ANOVA' subsection. The complete design of experiment with four significant process parameters is again executed on Moldflow to have better accuracy of the following regression equations. Then, response regression model will be established in which only significant process parameters are considered in 'Setting up the regression response model to create the complete dataset'

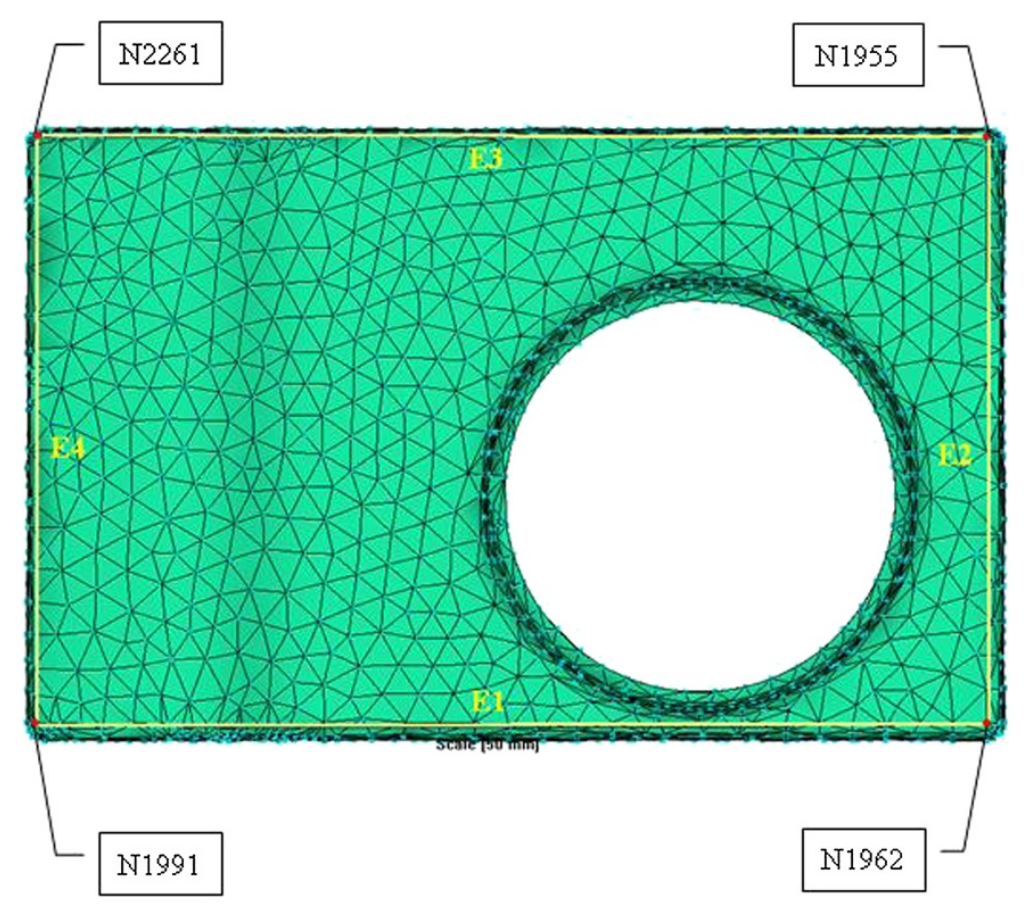

Figure 4 The nodes measured for the quality of parts. 
Table 3 Results of ANOVA

\begin{tabular}{|c|c|c|c|c|c|c|c|c|c|c|}
\hline & N1991 & N1962 & N1955 & N2261 & E1 & E2 & E3 & E4 & Volume & $U$ \\
\hline INT & & & & & & & & & () & $\bullet$ \\
\hline INP & () & ( ) & () & (?) & () & ○ & ○ & ○ & & $\bullet$ \\
\hline PP & () & () & () & () & (-) & (๑) & ○ & (๑) & & $\bullet$ \\
\hline PT & & & & & & & & & ○) & $\bullet$ \\
\hline \multicolumn{11}{|l|}{ COTI } \\
\hline \multicolumn{11}{|l|}{ COTE } \\
\hline \multicolumn{11}{|l|}{$\mathrm{MOO}$} \\
\hline MET & & & & & & & & & & \\
\hline MOTE & & & & & & & & & & \\
\hline
\end{tabular}

subsection. This subsection will also present how to create the complete dataset for finding the efficient combinations. Finally, 'Determining the efficient frontier of process parameters by DEA' subsection will discuss how to find the efficient frontier by DEA.

\section{Experimental design}

The Taguchi experimental design with orthogonal array is an efficient experimental design for fraction factorial design (Rose 1989; Montgomery 2005). Because there are nine process parameters considered in this research, complete experimental design is just too expensive to execute. Therefore, this research adopts the Taguchi experimental design with orthogonal array, L27, to perform the experiment on Moldflow. The experimental results of L27 is shown in Appendix A. Three levels of each process parameters are assigned to lower bound, mid-point, and upper bound of the range of operation listed in Table 2; for example, levels 1, 2 and 3 of injection time $x_{1}$ are $0.5,1$ and $1.5 \mathrm{~s}$, respectively.

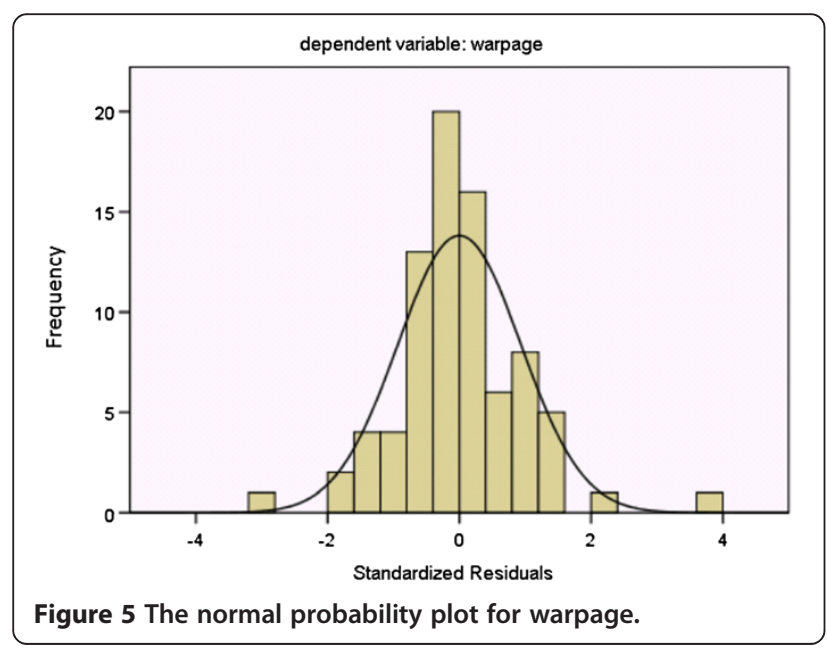

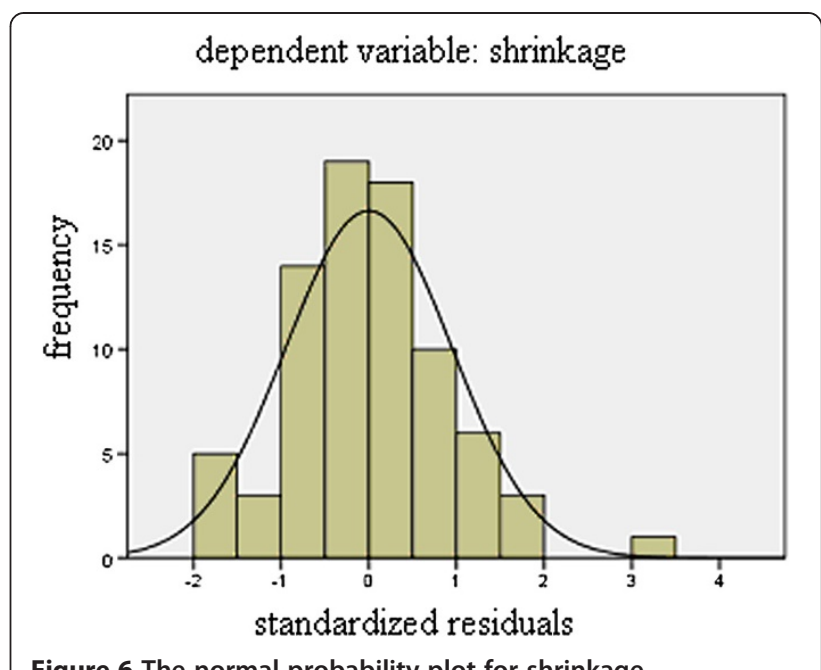

Figure 6 The normal probability plot for shrinkage.

\section{Finding significant process parameters by ANOVA}

In order to simplify the regression equations (and thus simplify the following procedure), ANOVA is firstly executed to find significant process parameters to affect the parts' three quality indices which will only be considered in the regression equations. The results are shown in Table 3. Each node represents the warpage at this node, each edge means the shrinkage at this edge, and the volume is the volumetric shrinkage at ejection in Table 3. The symbol '@) means the corresponding process parameter significantly affects the quality index under the significant level 0.05 in the figure. The last column of Table 3, U, is remarked by ' $\bullet$ ' if the corresponding process parameter significantly affects at least one quality index. From Table 3, only four process parameters are significant to affect at least one quality index, and

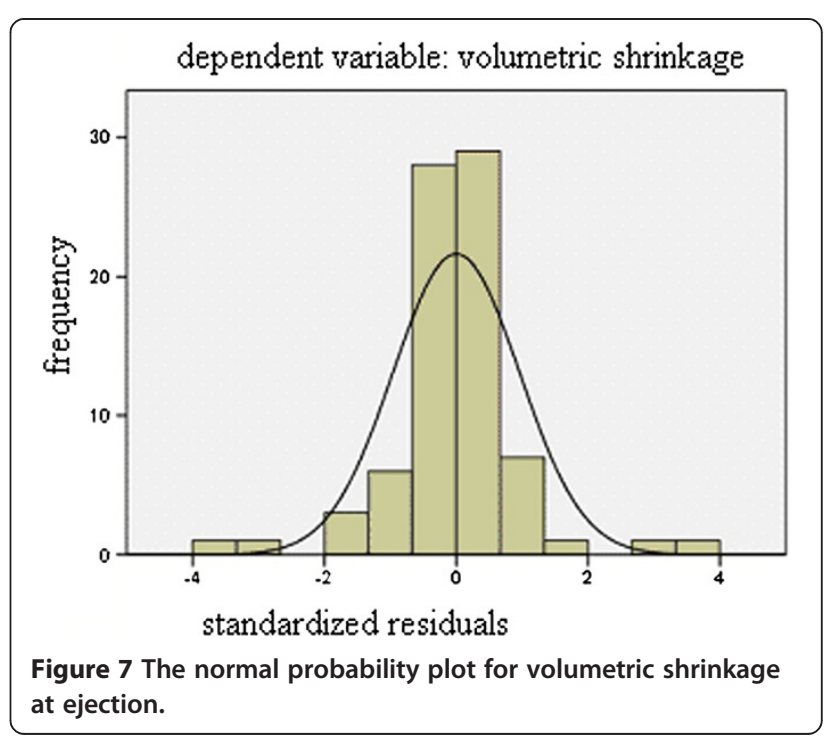


Table 4 Levels of process parameters

\begin{tabular}{lccccccc}
\hline Process parameter & L1 & L2 & L3 & L4 & L5 & L6 & L7 \\
\hline Injection pressure (MPa) & 100 & 110 & 120 & 130 & 140 & & \\
\hline Injection time (s) & 0.5 & 0.67 & 0.84 & 1 & 1.17 & 1.34 & 1.5 \\
\hline Packing pressure (MPa) & 80 & 86.67 & 93.34 & 100 & 106.67 & 113.34 & 120 \\
\hline Packing time (s) & 7.5 & 8.75 & 10 & 11.25 & 12.5 & & \\
\hline
\end{tabular}

hence only these four parameters are considered in the regression analysis in the next subsection.

\section{Setting up the regression response model to create the complete dataset}

To obtain a more complete efficient frontier for the process parameters, more data are required. The regression model, the response surface model, is utilized to create more data. In order to have better forecasting accuracy of the regression model, the complete experiment design with four significant process factors is executed again on Moldflow before the regression equations are established. The results are shown in the Appendix B.

The results of the complete experiment design with four significant process factors are then utilized to set up the second-order response surface model by the regression analysis of statistics software, SPSS. Three response surface equations for three quality indices are found below:

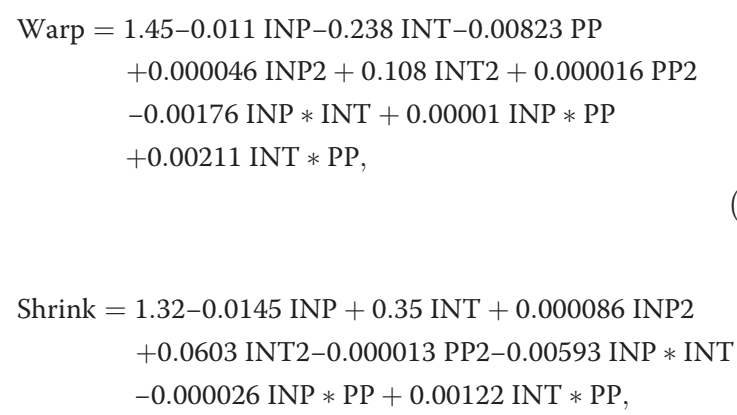

and

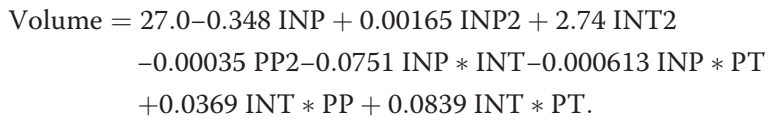

The normal probability plots are provided in Figures 5, 6,7 to justify the validity of the regression analysis.

To find a more complete efficient frontier of process parameters, more data are required. Regressed response
Table 5 DMUs on the efficient frontier

\begin{tabular}{lc}
\hline DMU & Score \\
\hline 560 & 100 \\
\hline 840 & 100 \\
\hline 871 & 100 \\
\hline 1,151 & 100 \\
\hline 1,186 & 100 \\
\hline 1,187 & 100 \\
\hline 1,188 & 100 \\
\hline 1,189 & 100 \\
\hline 1,190 & 100 \\
\hline
\end{tabular}

surface equations, Equations 1, 2, 3, are exploited to create more data points. Because DEA software, Banxia Frontier Analyst 3, has the limitation on the maximal number of data points (also called decision making units (DMUs)), the design of data points to be created is explained below. Based on the results of ANOVA, because injection time and packing pressure are more significant than the other two process parameters, there are seven levels selected for these two process parameters and five levels for the other two parameters. Therefore, there are $5 \times 7 \times 7 \times 5=1,225$ data points to be created by Equations 1, 2, 3. The levels of each process parameter are listed in Table 4 . Note that in Table 4, all levels of each parameter all fall its range of operation in Table 2.

\section{Determining the efficient frontier of process parameters by DEA}

DEA is a technique to evaluate the relative efficiency of many DMUs by analyzing multiple inputs and multiple outputs of each DMU. Its goal is to find the efficient DMUs, also called efficient frontier in the literature of DEA. This research uses the standard DEA Charnes, Cooper, and Rhodes (CCR) (Charnes et al. 1978) model to find the efficient frontier of DMUs which is created in the previous subsection. The mathematical model of DEA CCR is briefly outlined below. Suppose that there are $K$ DMUs, each of which consumes $N$ inputs and

\section{Table 6 The reference counts of the efficient DMUs}

\begin{tabular}{lc}
\hline DMU & Reference count \\
\hline 560 & 773 \\
\hline 840 & 624 \\
\hline 871 & 402 \\
\hline 1,151 & 182 \\
\hline 1,186 & 47 \\
\hline 1,187 & 0 \\
\hline 1,188 & 0 \\
\hline 1,189 & 0 \\
\hline 1,190 & 0 \\
\hline
\end{tabular}


Table 7 Levels of process parameters for efficient DMUs

\begin{tabular}{llccccc}
\hline & & \multicolumn{5}{c}{ DMU } \\
\cline { 2 - 7 } & & $\mathbf{5 6 0}$ & $\mathbf{8 4 0}$ & $\mathbf{8 7 1}$ & $\mathbf{1 , 1 5 1}$ & $\mathbf{1 , 1 8 6}$ \\
\hline Process parameter & $\mathrm{INP}$ & 120 & 130 & 130 & 140 & 140 \\
\cline { 2 - 7 } & $\mathrm{INT}$ & 0.67 & 0.84 & 1 & 1.17 & 1.34 \\
\cline { 2 - 7 } & $\mathrm{PP}$ & 120 & 120 & 120 & 120 & 120 \\
\cline { 2 - 7 } & $\mathrm{PT}$ & 12.5 & 12.5 & 7.5 & 7.5 & 7.5 \\
\cline { 2 - 7 } & COTI & 19 & 19 & 19 & 19 & 19 \\
\cline { 2 - 7 } & COTE & 25 & 25 & 25 & 25 & 25 \\
\cline { 2 - 7 } & MOO & 5 & 5 & 5 & 5 & 5 \\
\cline { 2 - 7 } $\begin{array}{l}\text { Quality index } \\
\text { (forecasting) }\end{array}$ & MET & 275 & 275 & 275 & 275 & 275 \\
\cline { 2 - 7 } & MOTE & 70 & 70 & 70 & 70 & 70 \\
\cline { 2 - 7 } & Whrink. & 0.0964 & 0.0930 & 0.0906 & 0.0997 & 0.1065 \\
\cline { 2 - 7 } Quality index (real) & 0.1397 & 0.1076 & 0.0814 & 0.0436 & 0.0126 \\
\cline { 2 - 7 } & Vol. & 1.9019 & 1.9418 & 2.0416 & 2.3027 & 2.5442 \\
\cline { 2 - 7 } & Warp. & 0.0796 & 0.0720 & 0.0780 & 0.0820 & 0.1114 \\
\cline { 2 - 7 } & Shrink. & 0.1232 & 0.9250 & 0.0835 & 0.0597 & -0.0948 \\
\cline { 2 - 6 } & Vol. & 2.0650 & 1.9610 & 2.0680 & 2.8260 & 3.3670 \\
\hline
\end{tabular}

produces $M$ outputs. Then, the DEA CCR model can be established as follows:

$$
\operatorname{Max} H_{K^{\prime}}=\frac{\sum_{m=1}^{M} U_{m} Y_{k^{\prime} m}}{\sum_{n=1}^{N} V_{n} X_{k^{\prime} n}}
$$

such that

$$
\begin{aligned}
& \frac{\sum_{m=1}^{M} U_{m} Y_{k m}}{\sum_{n=1}^{N} V_{n} X_{k n}} \leq 1 \\
& U_{m}, V_{n} \geq \varepsilon>0 \\
& m=1,2, \ldots, M \\
& n=1,2, \ldots, N \\
& k=1,2, \ldots, K,
\end{aligned}
$$

where $Y_{k m}$ is the value of the $m$ th output generated by the $k$ th DMU, $X_{k n}$ is the value of the $n$th input consumed by the $k$ th DMU, $V_{n}$ and $U_{m}$ are $X_{k n}$ 's and $Y_{k m}$ 's weights, respectively, whose values are determined by solving the model, $H_{k}$ is the relative efficiency of the $k$ th $\mathrm{DMU}$, and $\varepsilon$ is a small positive number. After solving the CCR DEA model, a DMU is on the efficient frontier if its relative efficiency, $H_{k}$, is equal to 1 .

Three quality indices, warpage, shrinkage, and volumetric shrinkage at ejection, are considered in this paper. Among these three indices, warpage is treated as the output, while shrinkage and volumetric shrinkage at ejection are two inputs in the DEA model. Because the output in DEA model needs to be maximized and warpage is apparently the minimized quality index, the transformation, 1-warpage, is adopted.

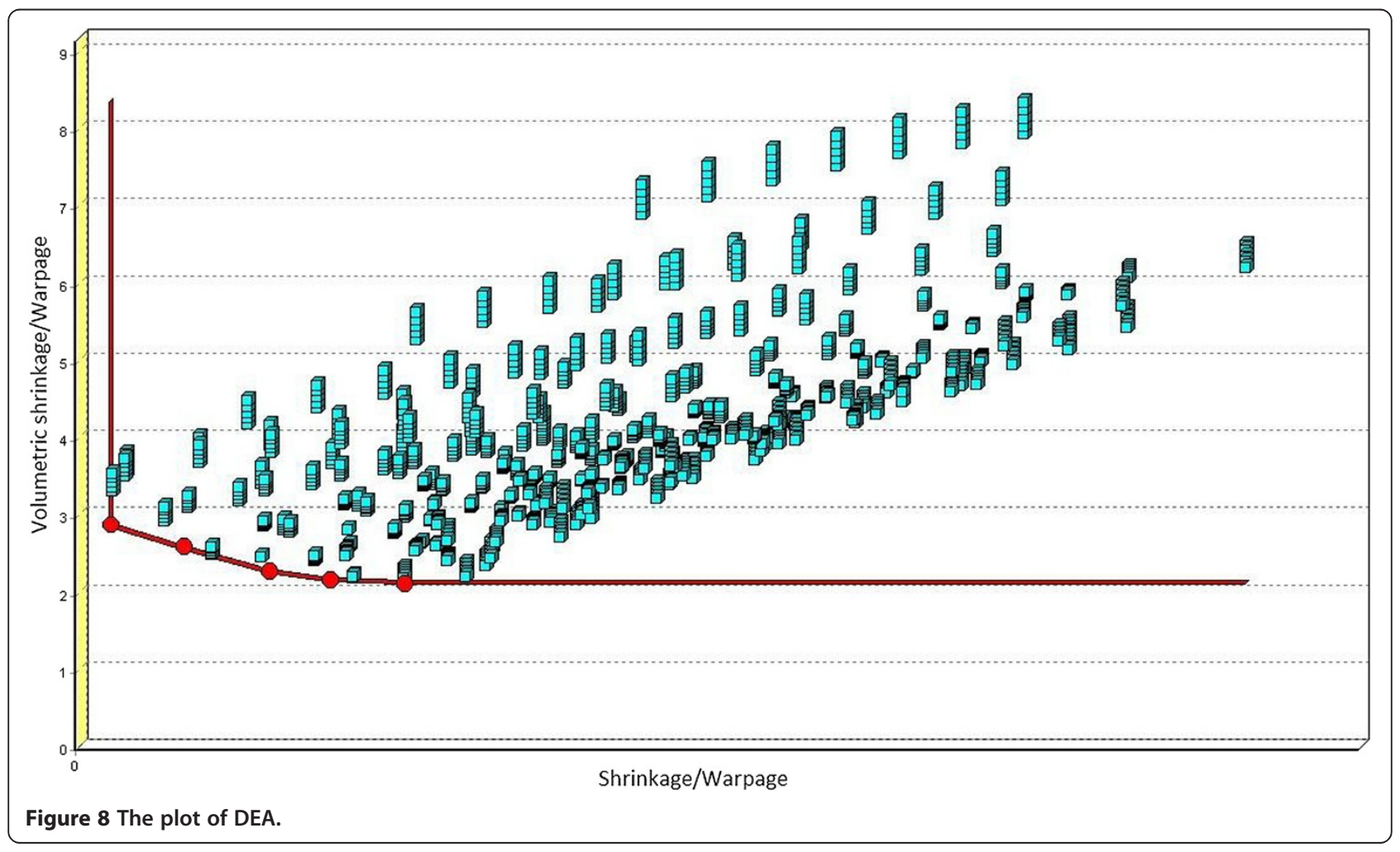


Table 8 Relatively efficient DMUs

\begin{tabular}{lc}
\hline DMU & Score \\
\hline 44 & 100 \\
\hline 45 & 100 \\
\hline 840 & 100 \\
\hline 871 & 100 \\
\hline 1,151 & 100 \\
\hline 54 & 97.82 \\
\hline 52 & 97.80 \\
\hline 53 & 97.13 \\
\hline 43 & 96.88 \\
\hline 560 & 94.19 \\
\hline
\end{tabular}

DMUs in italics represent the efficient ones suggested in this study.

The DEA software, Banxia Frontier Analyst 3, is used to find the efficient frontier of process parameters. The dataset used is the dataset of 1,225 data points created in the previous subsection. Each data point is treated as a DMU. After running Banxia Frontier Analyst 3, data points on the efficient frontier are found in Table 5. There are nine DMUs on the efficient frontier, among which five DMUs have at least one reference count as shown in Table 6. Therefore, these five DMUs with positive reference counts are treated as the efficient frontier of process parameters in this paper. The levels of each process parameter for these five DMUs are shown in Table 7, where the forecasting value of a quality index is its value derived from the corresponding regression equations and the real value of a quality index means its value by re-running Moldflow on this combination of process parameters. The plot of DEA results is shown in Figure 8.

To verify the efficiency of five DMUs found in this paper, we re-run Moldflow on each DMU and then the results are compared with those of $3^{4}=81$ data points which are utilized to set up the regression equations in 'Setting up the regression response model to create the complete dataset' subsection. The comparison is accomplished by executing DEA on 5 efficient DMUs found in this paper and 81 data points. The results are shown in Tables 8 and 9. From Table 9, it can be observed that

Table 9 Efficient DMUs with positive counts

\begin{tabular}{lc}
\hline DMU & Reference count \\
\hline 840 & 62 \\
\hline 1,151 & 12 \\
\hline 871 & 9 \\
\hline 45 & 9 \\
\hline 44 & 1 \\
\hline
\end{tabular}

among five efficient DMUs found in this paper, three DMUs are still on the efficient frontier and one DMU is relatively highly efficient with $94.18 \%$ DEA score. Only DMU 1,186 is not quite efficient with $71.28 \%$ DEA score, and this may be due to the error of the regression equation at this DMU. It is fair to suggest that the error induced by the regression equation at most of the points is fairly small. Therefore, the efficient frontier of process parameters found by this paper with only $108(=27+81)$ repeats of experiments can really provide good combinations of process parameters for decision making.

\section{Summary and conclusions}

Part quality for plastic injection molding is often evaluated by multiple interrelated quality indices, and each quality index is highly related with process parameters. This paper proposes a method of finding the complete efficient frontier of process parameters with only a few times of experiments when multiple quality indices are considered for plastic injection molding. The thin front cover of a digital camera is provided as the example of executing the method. Based on the literature, nine process parameters are considered in this research. The experimental design with the Taguchi orthogonal L27 is used to run the experiment on Moldflow. ANOVA is then executed to find significant parameters to affect the part's quality indices, and the results show that four out of nine parameters are significant with the significant level 0.05. In order to set up the complete efficient frontier of DEA analysis, more data are required, and the regression equations are used to create them. To have good accuracy of the multiple regressed equations, the complete experimental design with $3^{4}$ times (only four significant process parameters are considered) of experiments is again executed on Moldflow. The multiple regression equations are then set up and are used to produce the dataset for DEA analysis. The results of DEA analysis shows that the five combinations are on the efficient frontier.

To show the efficiency of these combinations suggested in this paper, DEA analysis is again conducted on them as well as the results of the experiments of $3^{4}$ times used for establishing multiple regression equations. The results show that only one combination is not as efficient mainly because of the error of the regressed equations at this combination. Hence, the method proposed here is believed indeed can find the efficient frontier of process parameters with only a few times of experiments.

The classic DEA method, CCR, is used in this paper; in the future, some other DEA methods, such as BCC, can be used, and the performance of each method can be compared. Another possible future research topic is to evaluate the performance of Moldflow analysis. 


\section{Appendix A}

The results of L27 are presented in Table 10.

Table 10 Experimental results of L27 array

\begin{tabular}{|c|c|c|c|c|c|c|c|c|c|}
\hline & N1991 & N1962 & N1955 & N2261 & E1 & E2 & E3 & E4 & Volume \\
\hline 1 & 0.2222 & 0.2118 & 0.2151 & 0.203 & 0.4014 & 0.1292 & 0.3728 & 0.171 & 4.384 \\
\hline 2 & 0.2137 & 0.2027 & 0.2077 & 0.1953 & 0.3856 & 0.1226 & 0.3598 & 0.1619 & 4.346 \\
\hline 3 & 0.2185 & 0.2082 & 0.2126 & 0.2001 & 0.395 & 0.1273 & 0.3681 & 0.1666 & 4.379 \\
\hline 4 & 0.1436 & 0.1322 & 0.1392 & 0.125 & 0.2532 & 0.0529 & 0.2346 & 0.0913 & 3.281 \\
\hline 5 & 0.1513 & 0.1416 & 0.1466 & 0.133 & 0.2675 & 0.0643 & 0.2475 & 0.1006 & 3.468 \\
\hline 6 & 0.1416 & 0.1301 & 0.137 & 0.1223 & 0.2491 & 0.0516 & 0.2308 & 0.0896 & 3.154 \\
\hline 7 & 0.1032 & 0.0902 & 0.098 & 0.0821 & 0.173 & 0.0035 & 0.1579 & 0.0379 & 3.936 \\
\hline 8 & 0.0927 & 0.0798 & 0.0877 & 0.0693 & 0.1497 & -0.0153 & 0.1321 & 0.0187 & 4.095 \\
\hline 9 & 0.0986 & 0.0867 & 0.0947 & 0.0783 & 0.165 & -0.0014 & 0.1503 & 0.0341 & 3.973 \\
\hline 10 & 0.1602 & 0.1564 & 0.1612 & 0.1521 & 0.2877 & 0.0609 & 0.2717 & 0.1046 & 4.337 \\
\hline 11 & 0.1455 & 0.1416 & 0.1412 & 0.1356 & 0.262 & 0.0564 & 0.2432 & 0.0959 & 3.938 \\
\hline 12 & 0.1414 & 0.1365 & 0.1354 & 0.1301 & 0.2526 & 0.0504 & 0.2309 & 0.0896 & 3.989 \\
\hline 13 & 0.0697 & 0.0593 & 0.0776 & 0.0559 & 0.083 & -0.0475 & 0.0739 & -0.013 & 2.063 \\
\hline 14 & 0.0677 & 0.0593 & 0.0718 & 0.0542 & 0.091 & -0.0379 & 0.0797 & -0.0041 & 2.018 \\
\hline 15 & 0.0735 & 0.0618 & 0.0824 & 0.0575 & 0.0873 & -0.0491 & 0.0779 & -0.0126 & 2.086 \\
\hline 16 & 0.1367 & 0.1358 & 0.1243 & 0.1288 & 0.2529 & 0.0685 & 0.2254 & 0.1026 & 3.593 \\
\hline 17 & 0.1352 & 0.134 & 0.1249 & 0.1289 & 0.2506 & 0.0647 & 0.2261 & 0.0994 & 3.369 \\
\hline 18 & 0.131 & 0.1303 & 0.1192 & 0.1246 & 0.243 & 0.059 & 0.2161 & 0.0937 & 3.526 \\
\hline 19 & 0.1446 & 0.1537 & 0.1601 & 0.1062 & 0.2521 & 0.0288 & 0.2252 & 0.0535 & 7.185 \\
\hline 20 & 0.1339 & 0.1483 & 0.1488 & 0.1027 & 0.247 & 0.0297 & 0.2139 & 0.0475 & 6.509 \\
\hline 21 & 0.1216 & 0.1423 & 0.144 & 0.1021 & 0.2177 & 0.0251 & 0.1904 & 0.0434 & 6.474 \\
\hline 22 & 0.1563 & 0.1809 & 0.1834 & 0.1507 & 0.3036 & 0.0629 & 0.2963 & 0.0983 & 7.855 \\
\hline 23 & 0.15 & 0.1893 & 0.1672 & 0.1452 & 0.3118 & 0.0546 & 0.2718 & 0.0897 & 7.12 \\
\hline 24 & 0.1786 & 0.2015 & 0.1828 & 0.1496 & 0.35 & 0.0686 & 0.3018 & 0.106 & 7.41 \\
\hline 25 & 0.0673 & 0.0611 & 0.0939 & 0.0325 & 0.0558 & -0.0288 & 0.0621 & -0.0166 & 3.294 \\
\hline 26 & 0.0951 & 0.0826 & 0.1094 & 0.051 & 0.1015 & -0.0014 & 0.1003 & -0.0039 & 3.055 \\
\hline 27 & 0.0794 & 0.0698 & 0.0991 & 0.0393 & 0.0651 & -0.0164 & 0.0728 & -0.0138 & 3.21 \\
\hline
\end{tabular}




\section{Appendix B}

The results of 81 are presented in Table 11 .

Table 11 Moldflow execution results

\begin{tabular}{|c|c|c|c|}
\hline & Warpage & Shrinkage & Volume shrinkage at ejection \\
\hline 1 & 0.2185 & 0.395 & 4.379 \\
\hline 2 & 0.2182 & 0.3944 & 4.378 \\
\hline 3 & 0.2169 & 0.3922 & 4.364 \\
\hline 4 & 0.1611 & 0.2867 & 3.611 \\
\hline 5 & 0.161 & 0.2863 & 3.61 \\
\hline 6 & 0.1601 & 0.2847 & 3.596 \\
\hline 7 & 0.1154 & 0.1973 & 2.724 \\
\hline 8 & 0.1156 & 0.1969 & 2.723 \\
\hline 9 & 0.1145 & 0.1951 & 2.706 \\
\hline 10 & 0.2006 & 0.3635 & 4.08 \\
\hline 11 & 0.2003 & 0.3629 & 4.079 \\
\hline 12 & 0.1998 & 0.3622 & 4.078 \\
\hline 13 & 0.1451 & 0.2556 & 3.288 \\
\hline 14 & 0.1452 & 0.2551 & 3.287 \\
\hline 15 & 0.1448 & 0.2545 & 3.286 \\
\hline 16 & 0.0982 & 0.1632 & 2.25 \\
\hline 17 & 0.098 & 0.1629 & 2.251 \\
\hline 18 & 0.0978 & 0.1626 & 2.249 \\
\hline 19 & 0.2271 & 0.4148 & 4.56 \\
\hline 20 & 0.2264 & 0.4134 & 4.516 \\
\hline 21 & 0.2253 & 0.4117 & 4.503 \\
\hline 22 & 0.1612 & 0.2931 & 3.683 \\
\hline 23 & 0.1607 & 0.2919 & 3.642 \\
\hline 24 & 0.1596 & 0.2905 & 3.627 \\
\hline 25 & 0.1111 & 0.1965 & 2.683 \\
\hline 26 & 0.1103 & 0.195 & 2.642 \\
\hline 27 & 0.1092 & 0.1931 & 2.264 \\
\hline 28 & 0.1952 & 0.3589 & 4.869 \\
\hline 29 & 0.195 & 0.3589 & 4.879 \\
\hline 30 & 0.1981 & 0.3646 & 4.958 \\
\hline 31 & 0.1472 & 0.265 & 4.016 \\
\hline 32 & 0.1471 & 0.2651 & 4.023 \\
\hline 33 & 0.1487 & 0.2679 & 4.073 \\
\hline 34 & 0.1068 & 0.1776 & 3.158 \\
\hline 35 & 0.107 & 0.1776 & 3.163 \\
\hline 36 & 0.1084 & 0.1805 & 3.2 \\
\hline 37 & 0.136 & 0.2522 & 3.551 \\
\hline 38 & 0.1335 & 0.2447 & 3.509 \\
\hline 39 & 0.1332 & 0.2471 & 3.506 \\
\hline 40 & 0.0982 & 0.1743 & 2.926 \\
\hline 41 & 0.096 & 0.1696 & 2.882 \\
\hline 42 & 0.0957 & 0.1691 & 2.883 \\
\hline 43 & 0.078 & 0.0835 & 2.068 \\
\hline 44 & 0.0775 & 0.0779 & 2.048 \\
\hline
\end{tabular}

Table 11 Moldflow execution results (Continued)

\begin{tabular}{|c|c|c|c|}
\hline 45 & 0.0778 & 0.0772 & 2.054 \\
\hline 46 & 0.1528 & 0.2846 & 3.924 \\
\hline 47 & 0.153 & 0.2847 & 3.939 \\
\hline 48 & 0.1517 & 0.2827 & 3.921 \\
\hline 49 & 0.1068 & 0.197 & 3.146 \\
\hline 50 & 0.1074 & 0.1973 & 3.155 \\
\hline 51 & 0.1063 & 0.1952 & 3.138 \\
\hline 52 & 0.0674 & 0.1021 & 2.015 \\
\hline 53 & 0.0678 & 0.1027 & 2.028 \\
\hline 54 & 0.0677 & 0.1007 & 2.014 \\
\hline 55 & 0.2068 & 0.3438 & 7.623 \\
\hline 56 & 0.1449 & 0.2523 & 3.853 \\
\hline 57 & 0.2079 & 0.3452 & 6.844 \\
\hline 58 & 0.1528 & 0.2605 & 4.782 \\
\hline 59 & 0.1465 & 0.2469 & 4.573 \\
\hline 60 & 0.1712 & 0.2751 & 6.899 \\
\hline 61 & 0.1617 & 0.2321 & 7.921 \\
\hline 62 & 0.1614 & 0.2345 & 6.631 \\
\hline 63 & 0.1618 & 0.2355 & 8.349 \\
\hline 64 & 0.1954 & 0.3269 & 7.239 \\
\hline 65 & 0.1214 & 0.2301 & 3.745 \\
\hline 66 & 0.1751 & 0.3106 & 6.779 \\
\hline 67 & 0.1362 & 0.1936 & 4.24 \\
\hline 68 & 0.1366 & 0.194 & 4.355 \\
\hline 69 & 0.1352 & 0.1922 & 4.284 \\
\hline 70 & 0.108 & 0.0802 & 3.177 \\
\hline 71 & 0.1049 & 0.0744 & 3.16 \\
\hline 72 & 0.1049 & 0.0746 & 3.165 \\
\hline 73 & 0.1021 & 0.1438 & 3.199 \\
\hline 74 & 0.1003 & 0.1455 & 3.186 \\
\hline 75 & 0.1004 & 0.1425 & 3.197 \\
\hline 76 & 0.1011 & 0.078 & 3.2 \\
\hline 77 & 0.0982 & 0.0732 & 3.206 \\
\hline 78 & 0.0981 & 0.0721 & 3.21 \\
\hline 79 & 0.1165 & -0.063 & 3.203 \\
\hline 80 & 0.1137 & -0.0656 & 3.22 \\
\hline 81 & 0.1132 & -0.0662 & 3.224 \\
\hline
\end{tabular}

\section{Acknowledgements}

The authors would like to thank financial support from the research project 98-2221-E-029-019, National Science Council of Taiwan. The authors are grateful to the expert anonymous reviewers and the editor-in-chief whose comments and suggestions considerably improved this article.

\section{Author details}

${ }^{1}$ Department of Computer Science and Information Management, Providence University, Taichung, Republic of China (Taiwan). ${ }^{2}$ Department of Industrial Engineering and Enterprise Information, Tunghai University, Taichung, Republic of China (Taiwan). 


\section{References}

Box GEP, Wilson KB (1951) On the experimental attainment of optimum condition. J Royal Statistic Soc 13:1-45

Castro CE, Ríos MC, Castro JM, Lilly B (2007) Multiple criteria optimization with variability considerations in injection molding. Polym Eng Sci 47(4):400-409

Charnes A, Cooper WW, Rhodes E (1978) Measuring the efficiency of decision making units. Eur J Oper Res 2:429-444

Chen ZB, Turng LS (2005) A review of current developments in process and quality control for injection molding. Adv Polym Technol 24(3):165-182

Chen RS, Lee HH, Yu CY (1997) Application of Taguchi's method on the optimal process design of an injection molded PC/PBT automobile bumper. Compos Struct 39:209-214

Chen WL, Huang CY, Hung CW (2010) Optimization of plastic injection molding process by dual response surface method with non-linear programming. Computations Engineering 27(8):951-966

Chiang KT, Chang FP (2007) Analysis of shrinkage and warpage in an injection-molded part with a thin shell feature using the response surface methodology. Int J Adv Manuf Technol 35:468-479

Erzurumlu T, Ozcelik B (2006) Minimization of warpage and sink index in injection-molded thermoplastic parts using Taguchi optimization method. Mater Des 27:853-861

Fan SK (2000) Quality improvement of chemical-mechanical wafer planarization process in semiconductor manufacturing using a combined generalized linear modeling - non-linear programming approach. Int J Prod Res 13:3011-3029

Huang MC, Tai CC (2001) The effective factors in the warpage problem of an injection-molded part with a thin shell feature. J Mater Process Technol 110:1-9

Kim BH, Lee BH (1997) Variation of part wall thicknesses to reduce warpage of injection-molded part: robust design against process variability. Polymer Plast Tech Eng 36(5):791-807

Kurtaran H, Erzurumlu T (2006) Efficient warpage optimization of thin shell plastic parts using response surface methodology and genetic algorithm. Int J Adv Manuf Technol 27:468-472

Kurtaran H, Ozcelik B, Erzurumlu T (2005) Warpage optimization of a bus ceiling lamp base using neural network model and genetic algorithm. J Mater Process Technol 169(3):314-319

Liao SJ, Hsieh WH, Wang JT, Su YC (2004a) Shrinkage and warpage prediction of injection-molded thin-wall parts using artificial neural networks. Polym Eng Sci 44:2029-2040

Liao SJ, Chang DY, Chen HJ, Ho JR, Yau HT, Hsieh WH (2004b) Optimal process conditions of shrinkage and warpage of thin-wall parts. Polym Eng Sci 44:917-928

Liu SJ, Chen CF (2002) Significance of processing parameters on the warpage of rotationally molded parts. J Reinf Plast Compos 21(8):723-733

Mackerle J (2005) Finite element modelling of ceramics and glass, an addendum - a bibliography (1998-2004). Eng Comput 22(3):297-373

Montgomery DC (2005) Introduction to Statistical Quality Control. Wiley, New York

Oktem H, Erzurumlu T, Uzman I (2007) Application of Tauguchi optimization technique in determining plastic injection molding process parameters for a thin-shell part. Mater Des 27:1271-1278

Ozcelik B, Erzurumlu T (2005) Determination of effecting dimensional parameters on warpage of thin shell plastic parts using integrated response surface method and genetic algorithm. Int Comm Heat Mass Tran 32(8):1085-1094

Ozcelik B, Erzurumlu T (2006) Comparison of the warpage optimization in the plastic injection molding using ANOVA, neural network model and genetic algorithm. J Mater Process Technol 171:437-445

Rose PJ (1989) Taguchi Techniques for Quality Engineering. McGraw-Hill, New York

Shoemaker J (2006) Moldflow Design Guide: A Resource for Plastics Engineers. Hanser Gardner Publications, Cincinnati

Walsh SF (1993) Shrinkage and warpage prediction for injection molded components. J Reinf Plast Compos 12:769-777

\subsection{6/2251-712X-9-25}

Cite this article as: Chen et al: Finding efficient frontier of process parameters for plastic injection molding. Journal of Industrial Engineering International 2013, 9:25

\section{Submit your manuscript to a SpringerOpen ${ }^{\odot}$ journal and benefit from:}

- Convenient online submission

- Rigorous peer review

- Immediate publication on acceptance

- Open access: articles freely available online

- High visibility within the field

- Retaining the copyright to your article

Submit your next manuscript at $\gg$ springeropen.com 